ARTICLE

https://doi.org/10.1057/s41599-020-0387-6

\title{
The interaction effect of online review language style and product type on consumers' purchase intentions
}

Zhen Liu', Shao-hui Lei ${ }^{2 \star}$, Yu-lang Guo ${ }^{2} \&$ Zhi-ang Zhou ${ }^{2}$

\begin{abstract}
Previous research has proved that online reviews on purchased goods can observably affect consumers' evaluation of products, purchase decisions, and purchase behaviors. This study classify online reviews into literal reviews and figurative reviews according to content features and language style. Product type is taken as a moderator to explore the impact of language style of online reviews on consumers' purchase intentions from the perspective of social presence. Based on two studies in China, the matching between online language style and product type is explored, which has an interactive effect on consumers' purchase intention. Social presence plays a mediating role. When purchasing search products, literal (vs. figurative) online reviews give consumers stronger social presence, resulting in higher purchase intentions. When purchasing experience products, consumers have stronger social presence because of figurative (vs. literal) online reviews, thus enhancing purchase intentions. The results not only expand the antecedent of social presence, but also offer several practical implications for online practitioners.
\end{abstract}

\footnotetext{
${ }^{1}$ Business Logistics Department, Guangdong Commercial Vocational Technical School, Guangzhou, China. ${ }^{2}$ School of Business Administration, Guangdong University of Finance and Economics, Guangzhou, China. *email: leishaohui123@163.com
} 


\section{Introduction}

nline reviews on purchased goods, as a means of word-ofmouth communication (Godes and Mayzlin, 2004), can influence consumers' evaluation of products, purchasing decisions and purchasing behaviors (Park and Kim, 2008; Daugherty et al., 2010; Chevalier and Mayzlin, 2006). Consumers have been used to evaluating the quality of products and services on e-commerce platforms, which further produce word of mouth (WOM) on the Internet. In accordance with surveys, $>70 \%$ of consumers refer to and even trust purchased consumers' comments about products and services, and about $85 \%$ consumers indicate that online reviews can influence their purchase behaviors (Shen et al., 2015). A large number of products can be sold on the internet in a short period of time, allowing customers to experience a variety of goods and greatly improving consumers' satisfaction. A considerable number of consumers not only pour attention to the information about products, but also focus on the purchased consumers' reviews (Li and Wang, 2018).

Purchase intention is the subjective probability that consumers choose to purchase products, which can predict consumers' purchasing behaviors in certain conditions (Mullet and Karson, 1985; Martins et al., 2019). Previous research on the impact of online reviews on purchase intention has focused primarily on quality, quantity, valence, similarity, etc. (Niu et al., 2016; Du et al., 2016; Jia and Liu, 2018). Du et al. (2016) explored the influence of different types of online reviews on consumers' purchase decisions from the perspectives of price, quantity and quality. Shi et al. (2018) explored the contradiction in online comments, finding that different types of contradictory comments have diverse impacts on consumers' attitudes and decisions. Thomas et al. (2019) pointed out that review quality and peripheral cues can determine the usefulness of reviews, which has positively influence on recipients' purchase intention. Less attention has been paid to the narrative style of reviews, while review contents have relatively high reference value in online consumption.

In recent years, an increasing number of literature about online reviews begins to pay attention to the influence of text content and linguistic style on consumers' attitudes and purchasing decisions (Willemsen et al., 2011; Schindler and Bickart, 2012; Ludwig et al., 2013; Wu et al., 2017). According to the content characteristics of online reviews, Willemsen et al. (2011) explored how expertize claims, review valence, and argumentation influence consumers' purchasing behavior via the path of perceived usefulness. Based on the matching between affective content and linguistic style of online reviews, Ludwig et al. (2013) explored the relationship between the interest group's linguistic style and positive changes in conversion rates. However, the above research fails to explore the intermediary mechanism, which needs to be further enriched.

Nevertheless, online shopping experience is relatively impersonal, objective, and anonymous, and it can be regarded as the lack of interpersonal warmth and sociability (Gefen and Straub, 2003; Van Der Heijden, 2003; Wang and Emurian, 2005). Therefore, we decided to look for a new perspective to make up for the lack of human warmth and sociability in online shopping experience. Besides, Pollio and Barlow (1975) showed that customers seldom use verbal description when conveying emotional states. They use some meaningful phrases to express their moods, such as "It's like I've lost a part of myself", or "there's a hole in my heart".

Social presence refers to the extent to which media allows users to perceive others as psychological existence (Fulk et al., 1987), which is an inherent attribute of communication medium (Short et al., 1976). From the perspective of social presence, Yu et al. (2017) initially explored the relationship model between online product information presentation and consumers' behavior intention in online shopping platforms, finding that product information is an important condition to induce social presence, thus enhancing the willingness to purchase. Therefore, this research aims to address these issues: Whether language style of online reviews can influence consumers' purchase decision? Is there a difference? How and why do language style of online reviews influence consumers' purchase decision?

\section{Literature review}

Online review and language style. Online reviews are consumers' voluntary feedback on purchase experience and have greatly potential information value for both consumers and enterprises (Godes and Mayzlin, 2004; Shen et al., 2015). Online reviews have become the focus of academic research, and the main research contents include three parts. Firstly, research on the emotion of online reviews gives priority to emotional tendency, emotional polarity, and emotional categorization (e.g., Shi et al., 2018; Ghasemaghaei et al., 2018). Through a crawler of online user reviews from 156 insurance companies, Ghasemaghaei et al. (2018) found that consumers' review sentiment was positively correlated with online review ratings, while review length had negative correlation with online review ratings. Secondly, some studies concentrate upon the perceived usefulness of online reviews (e.g., Hassanein and Head, 2007; Mudambi and Schuff, 2010). Based on perception theory, Mudambi and Schuff (2010) compared users' perceptions of different types of commodities, and proposed that the perceived usefulness of reviews can be affected by comment depth, comment polarity, and product type. Thirdly, research focuses on online WOM about online reviews (e.g., Godes and Mayzlin, 2004; Clemons and Hitt, 2006). Clemons and Hitt (2006) introduced the theories of hyperdifferentiation and resonance marketing, and proved that the market acceptance of products was influenced by the dual effects of dispersion and ordering of online reviews. Besides, many scholars pay attention to digital marketing strategies, asymmetric effects, star ratings, etc (e.g., Pelsmacker et al., 2018; Park and Nicolau, 2015; Vana and Lambrecht, 2018). However, there are few studies on the language style of online reviews (Willemsen et al., 2011; Ludwig et al., 2013).

Language style can comprehensively manifest the characteristics of language system and language application. Language can be used by individuals to achieve persuasive purpose in a certain communication state (Wang et al., 2016). Although language style is not related to language system, it is a way to understand the meaning through the discourse of subjective and objective conditions ( $\mathrm{Li}, 2002)$. There are different dimensions in the classification of language style. Pennebaker et al. (1997) divided conservational language into emotional words (e.g., happy, sad, angry) and cognitive process words (e.g., since, because, reason). According to the characteristics of text contents, Willemsen et al. (2011) classified online reviews into expertize claims, review valence and argument density, and explored how different language styles of review contents affect consumers' cognition and attitudes.

This study focuses on interpersonal warmth and human sociability, which is essentially an emotional transfer of users. According to the research results of Kronrod and Danziger (2013), user-generated content (UGC) is classified into literal language and figurative language. Literal language is the use of objective language to indicate the characteristics of product experience and parameter function without adding additional connotation. Figurative language refers to using indirect meanings of words and expressions to convey the additional 
connotation beyond the lexical meanings. There are many ways to reflect the style of literal language, such as storytelling, narration, and slogan type, which directly target the advertising theme and give the audience a clear and intuitive impression. Furthermore, individuals use figurative language to express their attitudes toward products and convey the meaning of transcendence through metaphor and exaggeration (Fogelin, 2011). Psycholinguistic research has revealed a positive correlation between the use of figurative language and emotional intensity in interpersonal communication (Caillies and Butcher, 2007). According to the definition of language style proposed by Kronrod and Danziger (2013), this study defined literal language style as a language material and a way in which people use unpretentious and objective words to describe things, and figurative language style as a language material and a way in which people use rich and slightly exaggerated words to describe things.

Product type: search products and experience products. Owing to the inability to directly contact products in the situation of online shopping, consumers attach great importance to the acquisition of information. As an important source of product information, online reviews are of great reference value to consumers' purchasing decisions. In information economics, products can be divided into experience products and search products according to consumers' knowledge of products (Nelson, 1970). In the context of search products, consumers can obtain product-related information relatively easily before purchasing. The quality of search products is mainly determined by objective attributes, which does not require strongly sensory experience, such as cameras, washing machines, and other products with detailed data. In contrast, consumers have difficulty in obtaining the information about experience products before purchasing, and they evaluate such products based on sensory experience. The quality of experience products is mainly determined by subjective experience (Huang et al., 2015), such as movies, music, and wine. The quality of search products is mainly determined by the search attributes. It has an objective evaluation standard for the products with the search attribute, which can be judged easily. Nevertheless, experience attributes determine the quality of experience product, and the standard mainly depends on consumers' subjective thinking. Owing to the lack of objective criteria for experience, subjective experience is required in the process of judgment (Mudambi and Schuff, 2010).

Telepresence and social presence. Telepresence is an individual sensory experience of the media environment (Biocca and Levy, 1995; Lombard and Ditton, 2010). The research on the sense of presence is originated from the fields of communication, distance education and interpersonal interaction. In recent years, it is also gradually rising in the field of ecommerce marketing. Telepresence can be divided into physical presence and social presence. Physical presence stresses the illusion of "being there" (Steuer, 1992), while social presence refers to psychological interaction and connection between users, reflecting a feeling of "being with others" (Ou et al., 2014; Short et al., 1976).

Social presence refers to the degree to which a person is viewed to be "real" and connected to others in the process of communication through the media (Short et al., 1976; Lombard and Ditton, 2010). Previous studies defined the social presence of a medium as its ability to convey information about facial expressions, posture, clothing, and nonverbal cues (Short et al., 1976). According to Lee (2004), there are three principal parts of social presence. the first, clients have been exposed to online platforms and immersed in a certain product. Second, consumers fully integrate their mind into a product on an online shopping platform via certain factors. Third, consumers have an illusion that they are directly exposed to products through information provided by others.

The existing research mainly explores the influence of online presence on consumers' purchasing behaviors from the perspective of trust (Zhao et al., 2015a, 2015b; Tang and Liao, 2016), and regards the sense of presence as a kind of "immersion experience" when browsing webpage (Skadberg and Kimmel, 2004). Klein (2010) found that social presence affects customers' enthusiasm for online stores through intermediary paths such as utilitarian value, trust and hedonic value. In the process of online shopping, the sense of presence can influence consumers' imagination of products. The sense of presence and interaction with consumers will affect the shopping pleasure (Song et al., 2007). Fortin and Dholakia (2005) studied the relationship between the vividness and interactive presentation of advertising information and consumers' attitudes and behaviors, which can positively influence interaction and presence to different degrees. Based on the planned behavior theory and the technology acceptance model, Hassanein and Head (2007) explored the influence of perceived social presence on consumers' attitudes towards online shopping website via perceived usefulness, trust, and enjoyment. Consumers' social presence describes the feeling of getting along with online sellers and other consumers. With warm and harmonious feeling, people are more willing to believe that the reviews are honest and kind, and they are more likely to generate a sense of contact with products, thus enhancing their evaluation of products and services (Zhao et al., 2015a, 2015b).

\section{Hypothesis development}

The interaction of online review language style and product type. Online reviews describe the actual use of products. When watching the reviews from customers who have purchased products, consumers can selectively capture valuable reviews that can help them complete their purchase tasks. In the situation of purchasing search products, consumers can check the information parameters of products by searching for information before purchasing, and formulate an objective criterion in the mind to evaluate products or services (Huang et al., 2015). Literal online review languages is that customers simply and clearly describe the objective facts of products through a simple and plain language (Kronrod and Danziger, 2013), such as the memory of mobile phones and the color difference of clothes. Therefore, in the context of purchasing search products, literal reviews offer consumers a more accurate basis for discriminating the objective attributes of products, and help consumers to make their purchase decisions.

In the situation of purchasing experience products, consumers have limited access to product information. Instead of measuring products on an objective basis, they rely more on the evaluation of other consumers to understand the performance and contents of products (Huang et al., 2015). Figurative online review language is that customers who have purchased the products express the subjective information of the products by using virtual metaphor and vividly depicting the subjective feelings of the parties (Fogelin, 2011). For example, vivid even exaggerated reviews of tourist products can induce consumers' impulsive consumption. Thus, compared to literal reviews, figurative reviews provide valuable information that meets the needs of individual's subjective experience in the context of purchasing experience products (Caillies and Butcher, 2007), thereby increasing consumers' purchase intention. 
Therefore, the following hypotheses are proposed:

H1. Compared with figurative reviews, literal reviews can improve consumers' willingness to purchase search products.

H2. Compared with literal reviews, figurative reviews can improve consumers' willingness to purchase experience products.

Mechanism: social presence. According to the social presence theory, language is an important conduit of social presence (Short et al., 1976). Online review features can instil a sense of social presence through socially rich text content (Gefen and Straub, 2003), just as letters and novels convey personal presence (Gefen and Straub, 2003; Riegelsberger et al., 2003). Choosing online review language style can help create a sense of psychological closeness and human warmth (Vries, 2006). Advertising studies have revealed that imaginative texts may evoke complex and pleasurable fantasies involving the use of products (Fiore and $\mathrm{Yu}$, 2010), which in turn reinforce product preference and purchase probability (Oliver and Mitchell, 1993).

When browsing online reviews, consumers can selectively capture valuable information to accomplish their purchase tasks. In the process verifying comments and thoughts, a sense of social presence will be induced and deepen the cognition of products. In the situation of purchasing search products, consumers can evaluate the quality of products according to objective criteria (Nelson, 1970). In the face of literal online reviews, consumers will maximize their utility in line with their psychological reference. Audiences feel that the reviewers are thinking of their own needs in the same place. They will treat the reviewers as "real person" around them and establish a social and emotional connection. In turn, viewers will be more willing to believe in the authenticity of the comment contents (Yu et al., 2017).

In the situation of purchasing experience products, consumers are unable to evaluate the subjective information of products according to the objective attributes, and they need to understand the subjective information of products via the subjective taste or the purchasing experience of others (Nelson, 1970; Huang et al., 2015). When the online review is a figurative language style, it can depict the subjective feelings of experience products more vividly, and consumers can have an emotional response and easily immerse in the situation of experiencing product (Zhao et al., 2015a, 2015b). For example, watching a figurative film review can produce a deeper sense of substitution for the plots in a film.

Therefore, the following hypotheses are formed:

H3. In the context of search products, social presence mediates the relationship between the language style of online reviews and consumers' purchase intention.

H4. In the context of experience products, social presence mediates the relationship between online language styles and consumers' purchase intention.

Research model. The conceptual model is presented in Fig. 1.

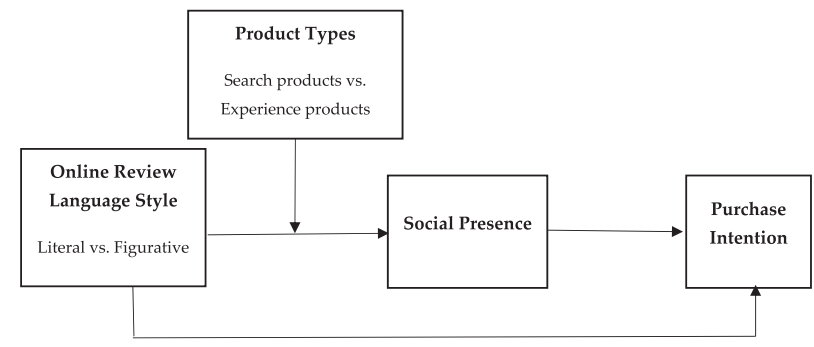

Fig. 1 Conceptual model. This figure is the proposed research model of this paper.

\section{Experiment 1: the matching of language style and product types on purchase intention \\ Experimental design. A total of 138 undergraduates from} Guangzhou, China were recruited to participate in this study for a small monetary payment. They were assigned randomly to one of 4 cells of a 2 (language style: literal vs. figurative) $\times 2$ (product type: search product vs. experience product) between-subject design. After removing 12 invalid questionnaires, 126 valid questionnaires were collected with an effective rate of $91.3 \%$.

Stimulus materials. The group of search products asked the participants to imagine purchasing a digital camera, while the group of experience products asked the participants to imagine buying a coat. The digital camera and the coat were selected from the experimental operation of Hassanein and Head (2007) and Mudambi and Schuff (2010). The questionnaire presents the product parameters of the digital camera or the coat, as well as the reviews of the consumers who bought the digital camera or the coat. The reviews were collected from taobao.com. The materials of the literal group are such as "this dress will keep me warm in winter", while the materials of the figurative group are such as "wearing this dress can become a fairy!" (see Supplementary Appendix).

Measures. The measurement scales in formal experiments involve manipulation checks (online review language style and product type) and dependent variables (purchase intention). Firstly, after reading the definition of language style, participants were required to score the type of review style. Secondly, after reading the definition of product type, participants were required to score the type of product. Finally, participants filled out the scale of purchase intention with three items, which was developed by Kronrod and Danziger: "The information in the online comments made me be willing to buy this product", "The information in the online comments made me decide to buy this product", and "I will also consider coming to this online store to buy this product". Cronbach's $\alpha$ coefficient of purchase intention is 0.953 , which is higher than the specified coefficient of 0.7 , indicating that the scale has good internal consistency (Bonett and Wright, 2015). The 7-point Likert scale was used for all of the above scales, from 1 (not at all) to 7 (very much).

\section{Results}

Manipulation check. Participants rated the typicality of the language used in the reviews and the products. In the manipulation of language style (1-literalness, 7-figurativeness), the figurative description is much more figurative $\left(M_{\text {figurative }}=5.71\right)$ than the literal description $\left(M_{\text {literal }}=2.19, F(1,124)=247.58, p<0.01\right)$, indicating that participants have perceived a significant difference in figurativeness of the description. The data results demonstrate that the manipulation of language style is successful. In the manipulation of product type (1-search product, 7 -experence product), the results of the independent sample $t$-test indicate a significant difference between the coat and the digital camera $\left(M_{\text {coat }}=5.63>M_{\text {camera }}=2.33, F(1,124)=190.96, p<0.01\right)$. The results show that the product type is successfully manipulated.

Dependent variable. A two-way analysis of variance (ANOVA) result reveals that neither online review language style $[F$ $(1,122)=0.009, p=0.926]$ nor product type $[F(1,122)=1.766$, $p=0.186]$ has significant main effect. In the second-order interaction term, there is a significant interactive effect between product type and language style $[F(1,122)=10.915, p=0.001]$. The results of the simple effect test are shown in Fig. 2. In the context of purchasing search products, literal online reviews can 


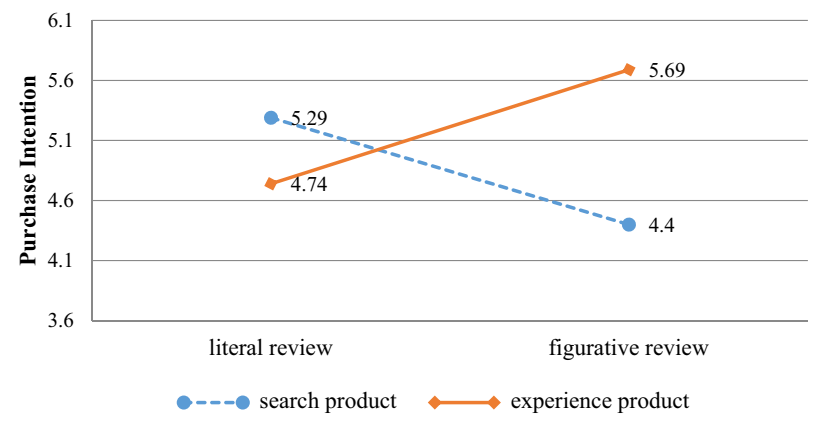

Fig. 2 Interactive effect of online review language styles and product

types. In study 1 , in the context of purchasing search products, literal online reviews can enhance consumers' purchase intention more significantly than figurative online reviews $\left[M_{\text {figurative }}=4.40, M_{\text {literal }}=5.29, p<0.05\right]$. In the context of purchasing experience products, figurative online reviews can enhance consumers' purchase intention compared with literal online reviews $\left[M_{\text {figurative }}=5.69, M_{\text {literal }}=4.74, p<0.05\right]$.

enhance consumers' purchase intention more significantly than figurative online reviews $\left[M_{\text {figurative }}=4.40, M_{\text {literal }}=5.29, F(1\right.$, $122)=5.155, p=0.025]$. In the context of purchasing experience products, figurative online reviews can enhance consumers' purchase intention compared with literal online reviews $\left[M_{\text {figurative }}=5.69, M_{\text {literal }}=4.74, F(1,122)=5.769, p=0.018\right]$. In summary, both $\mathrm{H} 1$ and $\mathrm{H} 2$ are supported.

Discussion. The results verify that both language style of online reviews and product type can influence consumers' purchase intention. Compared with figurative reviews, literal reviews can improve consumers' willingness to purchase search products (but not experience products). Figurative reviews can improve consumers' willingness to purchase experience products (but not search products) more significantly than literal reviews. Hypothesis 1 and Hypothesis 2 are supported. In order to enhance the universality of the research results, we selected another set of stimulus materials in the follow-up experiment to examine the mediating role of social presence.

\section{Experiment 2: the mediating role of social presence}

Experimental design. A total of 143 undergraduates from Guangzhou, China were recruited to participate in this study for a small monetary payment, who were different from the participants of experiment 1 . Next, the participants were assigned randomly to one of 4 cells of a 2 (language style: literal vs. figurative) $\times 2$ (product type: search product vs. experience product) between-subject design. After removing 18 invalid questionnaires, 125 valid questionnaires were collected with an effective rate of $87.4 \%$.

Stimulus materials. The participants in the group of search product were asked to imagine purchasing a mobile phone, while the participants in the group of experience product were required to imagine booking a hotel. The mobile phone and the hotel were selected from the experimental operation of Kronrod and Danziger's research. The questionnaire presented the product parameters of the phone or the hotel and the purchase reviews of the customers who had bought the phone or booked the hotel. The reviews were collected from taobao.com. (see Supplementary Appendix).

Measures. Measurement scales in formal experiments involve manipulation check (online review language style, product type), mediator (social presence), and dependent variables (purchase
Table 1 Reliability test of measure items.

\begin{tabular}{|ccc|} 
& Items & Cronbach's $\boldsymbol{\alpha}$ \\
\hline Social presence & 3 & 0.920 \\
Purchase intention & 3 & 0.918 \\
\hline
\end{tabular}

intention). Firstly, after reading the definition of language style, the participants were required to score the type of review style. Secondly, after reading the definition of product type, the participants were asked to score the type of product. Thirdly, the participants filled out the scale of purchase intention with three items developed by Kronrod and Danziger (2013). Finally, the participants filled out the scale of social presence developed by Hassanein and Head (2007): "There is a sense of human contact on this website", "There is a sense of sociability on this website", "There is a sense of human warmth on this website". The 7-point Likert scale was used for all of the above measures, from 1 (not at all) to 7 (very much).

\section{Results}

Manipulation check. Participants rated the typicality of the language used in the reviews and the products. In the manipulation of language style (1-literalness, 7-figurativeness), the figurative description was significantly more figurative $\left(M_{\text {figurative }}=6.04\right)$ than the literal description $\left[M_{\text {literal }}=1.85, F(1,123)=254.41, p<\right.$ 0.001 ], indicating that participants perceived a significant difference in the figurativeness of the descriptions. The data result demonstrates that the manipulation of language style is successful. In the manipulation of the product type (1-search product, 7 experence product), the mean value of the hotel $\left(M_{\text {hotel }}=6.08\right)$ is much larger than the average value of the mobile phone $\left[M_{\text {phone }}=1.90, F(1,123)=507.73, p<0.001\right]$. The data results show that the product type is successfully manipulated.

Reliability test. SPSS 22.0 was used to test the reliability of purchase intention and social presence (see Table 1). The Cronbach's $\alpha$ of purchase intention is 0.918 , and the Cronbach's $\alpha$ of social presence is 0.920 , both of which are $>0.7$, indicating that the scale has a good internal consistency (Bonett and Wright, 2015).

\section{Hypothesis testing.}

Dependent variable. A two-way ANOVA result reveals that neither online review language style type $[F(1,121)=0.866$, $p=0.354]$ nor product type $[F(1,121)=0.438, p=0.509]$ has significant main effect. In the second-order interaction term, there is a significant interaction effect between product type and language style $[F(1,121)=15.272, p=0.000]$. The results of the simple effect analysis are shown in Fig. 3. In the context of purchasing search products, literal online reviews bring higher consumers' purchase intention than figurative online reviews $\left[M_{\text {figurative }}=4.25, M_{\text {literal }}=5.60, F(1,121)=11.614\right.$, $p=0.001]$. In the context of purchasing experience product, figurative online reviews can enhance consumers' purchase intention more significantly than literal online reviews $\left[M_{\text {figurative }}=5.16, \quad M_{\text {literal }}=4.32, \quad F(1, \quad 121)=4.467\right.$, $p=0.037]$. Both hypothesis 1 and hypothesis 2 are supported.

Moderated mediation analyses. To evaluate the internal mechanism of the observed effect, the indirect effect was examined following the procedure outlined by Hayes's model 8 (Chen et al., 2013). A total of 5000 bootstrap samples were used in the analysis, showing the mediating effect of product types, and $95 \%$ CI is $[1.5772,3.6496]$, not including 0. Therefore, there is a moderated mediating effect. Specifically, 


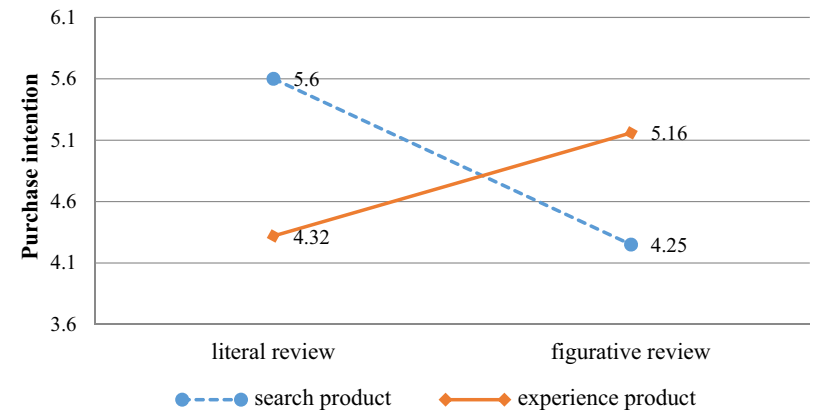

Fig. 3 Interactive effect of online review language styles and product

types. In study 2 , in the context of purchasing search products, literal online reviews bring higher consumers' purchase intention than figurative online reviews $\left[M_{\text {figurative }}=4.25, M_{\text {literal }}=5.60, p=0.001\right]$. In the context of purchasing experience product, figurative online reviews can enhance consumers' purchase intention more significantly than literal online reviews $\left[M_{\text {figurative }}=5.16, M_{\text {literal }}=4.32, p<0.05\right]$.

in the context of search products, the mean value of the indirect effect is -1.5056 , and $95 \%$ CI is $[-2.1618,-0.9249]$, not including 0 . Social presence has significant mediating effects in the context of purchasing search product, supporting hypothesis 3. Similarly, in the context of purchasing experience goods, the mean value of the indirect effect is 1.0575 , and $95 \%$ $\mathrm{CI}$ is $[0.5273,1.6639]$, not including 0 , indicating the significant mediating effect of social presence, supporting hypothesis 4 .

In conclusion, $\mathrm{H} 3$ and $\mathrm{H} 4$ are supported by the data results. In the context of purchasing search products, literal online reviews bring consumers with a stronger sense of social presence than competing online reviews, thereby enhancing their purchase intention. In the context of purchasing experience goods, figurative online reviews can improve consumers' purchase intention by bringing consumers with a stronger sense of social presence than literal online reviews.

\section{Conclusion and discussion}

This study explored the impact of language style of online reviews and product type on consumers' purchase intention from the perspective of social presence. The match between online language style and product type has an interactive effect on consumers' purchase intention, and social presence plays a mediating role. Specifically, this study has drawn the following conclusions.

Research conclusions. First of all, the interaction effect between online review language style and product type can influence consumers' purchase intention. By carrying out two experiments, it can be found that literal language style can enhance consumers' purchase intention in the context of purchasing search products. When purchasing search products, consumers often search for product parameters first and then establish an objective judgment standard. Literal online reviews provide consumers with a more direct and objective basis, and help them to complete the purchasing task. In the context of purchasing experience products, figurative reviews lead to higher purchase intention than literal reviews. Now that the product attributes are more dependent on subjective taste and cannot be directly judged before purchase due to the lack of objective evaluation criteria, consumers pay more attention to the experience of using products. Since consumers cannot directly experience products, they have to refer to the reviews of others who have purchased the products to obtain more product information. Through the connotation expressed by online reviews, consumers will make a comprehensive decision to purchase or not. Therefore, the information provided by the figurative language style is not only realistic, but also vividly describes the experience process of the parties.

Second, social presence plays a mediating role in the relationship between online review language style and consumers' purchase intention. In the context of purchasing search products, consumers who view literal online reviews can beter understand the objective attributes of products, and feel that their own immersion directly contact with the products, thus increasing the trust in products (Skadberg and Kimmel, 2004; Zhao et al., 2015). In the context of purchasing experience products, since the product attributes are more dependent on subjective experience and cannot be judged directly before purchasing, consumers can easily enter the product experience context through a figurative online review language, and fully understand the relevant information about products, which is helpful for consumers to make purchase decisions.

Theoretical contributions. First, this study enriched the literature on the language style of online reviews, and explored the effect of the matching between language style and product type on consumers' purchase intention. Based on the research of Kronrod and Danziger in 2013, language style was divided into literal language style and figurative language style. Besides, in the situation of online shopping, products were classified into search products and experience products according to information economics to explore the matching degree of language style of online reviews and product type.

Second, this study expanded the antecedents of social presence. Previous literature mainly viewed social presence as an antecedent variable, which can increase consumers' trust, perceived usefulness, and enjoyment, thereby enhancing their purchase intention (Gefen and Straub, 2004; Zhao et al., 2015a, 2015b; Tang and Liao, 2016). There is a lack of research on the antecedent variables of social presence. Based on the social presence theory, we have explored language style as the antecedent variable that can induce social presence. The research results have theoretical significance for making up for the lack of actual experience in online situations. To some extent, this study also complements the limited research on online shopping experience.

Practice implications. On the one hand, when classifying the language style of online reviews, the corresponding styles of reviews can be selected for different types of products to provide valuable information to consumers more quickly and accurately, and reduce information search cost. Marketing managers should highlight search products, such as digital products and wearable device, and selectively prioritizing them to further persuade consumers; for experience products, such as, coat and shoes, marketing managers can post vivid visual figurative review, attracting consumers' attention, and further bringing them into the virtual experience.

On the other hand, online shopping websites can establish a big data platform to understand consumers' daily shopping habits, grasp consumers' preference for product consumption, specifically the target customers, and post online reviews with different language styles to attract consumers and enhance consumers' social presence. Furthermore, online stores can use online reviews to build information communication channels between potential consumers and consumers who have bought products, and improve potential consumers' social presence and purchase conversion rate. 
Limitations and future research. Analyzing the impact of the matching between review style and product type on consumers' purchase intention through two experiments has certain theoretical and practical values. However, we acknowledge a few shortcomings of this study to be improved. Firstly, this study only considers the selection of the content of favorable reviews, while consumers have differential attitudes towards different types of online reviews (Niu et al., 2016; Jia and Liu, 2018). Future research can be extended to the field of medium and negative reviews. Secondly, this paper analyzes the influence of the language style of online reviews on consumers' purchasing intention from the perspective of social presence. Future research can explore the relationship from other perspectives. Thirdly, previous studies have shown that time interval has a definite impact on the relationship between online reviews and consumers' purchase intention (Wang et al., 2015). In the future, the impact of online review language style on consumers' purchase intention can be analyzed considering the integration of time dimension. Fourthly, individual differences may be a potential moderator, including readers and reviewers, which can influence the judgment and decision of the audience on online reviews. The involvement and expertize of readers can influence how online comments are interpreted (Racherla et al., 2012). Furthermore, reviewers' reputation can also affect consumers' attitudes towards reviews (Scholz and Dorner, 2013). Individual differences deserve further exploration in the future. Finally, this study chooses the experimental method and eliminates a number of interfering factors. However, in real life, consumers' purchasing choices are affected by various factors such as income and age. Other methods, such as the questionnaire method and filed study, may be considered to further optimize the conclusions in the future. Also, all participants are from China, which belongs to an Asian context, and cannot represent all countries and cultures. Future research can be carried out in a wider scope (e.g., Global South) to obtain more comprehensive data (Dados and Connell, 2012). These interesting issues are worthy of further examination.

\section{Data availability}

Owing to privacy reasons, the datasets analyzed during the current study are not publicly available but are available from the corresponding author on reasonable request.

Received: 19 July 2019; Accepted: 23 December 2019;

Published online: 21 January 2020

\section{References}

Biocca F, Levy MR (1995) Communication in the age of virtual reality. Lawrence Erlbaum Associates, New Jersey

Bonett DG, Wright TA (2015) Cronbach's alpha reliability: interval estimation, hypothesis testing, and sample size planning. J Organ Behav 36(1):3-15

Caillies S, Butcher K (2007) Processing of idiomatic expressions: evidence for a new hybrid view. Metaphor Symb 22(1):79-108

Chen R, Zheng LH, Liu WJ (2013) Mediation: principles, procedures, bootstrap method and applications. J Mark Sci 9(4):120-135. (in Chinese)

Chevalier JA, Mayzlin D (2006) The effect of word of mouth on sales: online book reviews. J Mark Res 43(3):345-354

Clemons EK, Hitt GLM (2006) When online reviews meet hyperdifferentiation: a study of the craft beer industry. J Manag Inf Syst 23(2):149-171

Daugherty T, Li H, Biocca F (2010) Consumer learning and the effects of virtual experience relative to indirect and direct product experience. Psychol Mark 25(7):568-586

Dados N, Connell R (2012) The global south. Contexts 11(1):12-13

Du XM, Ding JY, Xie ZH et al. (2016) An empirical study on the impact of online reviews on consumers' purchasing intention. Manage. Rev. 28(3):173-183 (in Chinese)
Fiore AM, Yu H (2010) Effects of imagery copy and product samples on responses toward the product. J Interact Mark 15(2):36-46

Fogelin RJ (2011) Figuratively speaking. Oxford University Press, London

Fortin DR, Dholakia RR (2005) Interactivity and vividness effects on social presence and involvement with a web-based advertisement. J Bus Res 58 (3):387-396

Fulk J, Schmitz J, Power GJ (1987) A social information processing model of media use in organizations. Commun Res 14(5):520-552

Gefen D, Straub D (2003) Managing user trust in b2c e-services e-Service J 2 (2): $7-24$

Gefen D, Straub DW (2004) Consumer trust in B2C e-Commerce and the importance of social presence: experiments in e-Products and e-Services. Int J Manag Sci 32(6):407-424

Ghasemaghaei M, Eslami PS, Deal K, Hassanein K (2018) Reviews' length and sentiment as correlates of online reviews' ratings. Internet Res 28(3):544-563

Godes D, Mayzlin D (2004) Using online conversations to study word-of-mouth communication. Mark Sci 23(4):545-560

Hassanein K, Head M (2007) Manipulating perceived social presence through the web interface and its impact on attitude towards online shopping. Int J HumComputer Stud 65(8):689-708

Heijden HVD (2003) Factors influencing the usage of websites: the case of a generic portal in the Netherlands. Inf Manag 40(6):541-549

Huang J, Guo YL, Wang C, Yan L (2015) You touched it and i'm relieved! the effect of online review's tactile cues on consumer's purchase intention. J Mark Sci 11(1):133-151. (in Chinese)

Jia Y, Liu IL (2018) Do consumers always follow "useful" reviews? The interaction effect of review valence and review usefulness on consumers' purchase decisions. J Assoc Inf Sci Technol 69(11):1304-1317

Klein LR (2010) Creating virtual product experiences: the role of social presence. J Interact Mark 17(1):41-55

Kronrod A, Danziger S (2013) “Wii Will Rock You!" the use and effect of figurative language in consumer reviews of hedonic and utilitarian consumption. J Consum Res 40(4):726-739

Lee KM (2004) The multiple source effect and synthesized speech. Hum Commun Res 30(2):182-207

Li HL, Wang XY (2018) The effect of online user reviews on customer value creation: from the perspective of price decision. Price: Theory Pract 38 (1):150-153. (in Chinese)

Li YH (2002) A review on the studies of the definition of language style since 1949. Appl Linguist 11(1):100-106. (in Chinese)

Lombard M, Ditton T (2010) At the heart of it all: the concept of presence. J Computer-mediated Commun 3(2):1-8

Ludwig S, Ruyter K, Friedman M et al. (2013) The influence of affective content and linguistic style matches in online reviews on conversion rates. J Mark 77 (1):87-103

Martins J, Costa C, Oliveira T, Gonçalves R, Branco F (2019) How smartphone advertising influences consumers' purchase intention. J Bus Res 94:378-387

Mudambi SM, Schuff D (2010) What makes a helpful online review? a study of customer reviews on amazon.com. MIS Q 34(1):185-200

Mullet GM, Karson MJ (1985) Analysis of purchase intent scales weighted by probability of actual purchase. J Mark Res 22(1):93-96

Nelson P (1970) Information and consumer behavior. J Political Econ 78 (2):311-329

Niu GF, Li GQ, Geng XX et al. (2016) The impact of online reviews' quality and quantity on online purchasing intention: the moderating effect of need for cognition (in Chinese). J Psychological Sci 39(6):1454-1459

Oliver RL, Mitchell RDJ (1993) Imaging and analyzing in response to new product advertising. J Advertising 22(4):35-50

Ou CX, Pavlou PA, Davison RM (2014) Swift guanxi in online marketplaces: the role of computer-mediated communication technologies. MIS Q 38 (1):209-230

Park DH, Kim S (2008) The effects of consumer knowledge on message processing of electronic word-of-mouth via online consumer reviews. Electron Commer Res Appl 7(4):399-410

Park S, Nicolau JL (2015) Asymmetric effects of online consumer reviews. Ann Tour Res 50:67-83

Pelsmacker DP, Tilburg VS, Holthof C (2018) Digital marketing strategies, online reviews and hotel performance. Int J Hospitality Manag 72:47-55

Pennebaker JW, Mayne TJ, Francis ME (1997) Linguistic predictors of adaptive bereavement. J Personal Soc Psychol 72(4):863-871

Pollio HR, Barlow JM (1975) A behavioural analysis of figurative language in psychotherapy: one session in a single case-study. Lang Speech 18(3):236-254

Racherla P, Mandviwalla M, Connolly DJ (2012) Factors affecting consumers' trust in online product reviews. J Consum Behav 11(2):94-104

Riegelsberger J, Sasse MA, Mccarthy JD (2003) Shiny happy people building trust? Photo on e-Commerce websites and consumer trust. Sigchi Conference on Human Factors in Computing Systems. ACM 
Schindler RM, Bickart B (2012) Perceived helpfulness of online consumer reviews: the role of message content and style. J Consum Behav 11(3):234-243

Scholz M, Dorner V (2013) The recipe for the perfect review? Bus Inf Syst Eng 5 (3):141-151

Shen L, Zhuang GJ, Guo R et al. (2015) E-purchase intention for complex buying behaviors: a grounded-theory research based on online customer reviews about E-purchase of cars (in Chinese). Manag Rev 27(9):221-230

Shi WH, Zhang Q, Cai JL (2018) The impact of contradictory online reviews on ambivalent attitude and purchase intention. Manag Rev 30(7):77-88

Short J, Williams E, Christie B (1976) The social Psychology of social communications. Wiley, London

Skadberg YX, Kimmel JR (2004) Visitor's flow experience while browsing a web site: its measurement, contributing factors and consequences. Computers Hum Behav 20(3):403-422

Song K, Fiore AM, Park J (2007) Social presence and fantasy in online apparel shopping experience. J Fash Mark Manag 11(4):553-570

Steuer J (1992) Defining virtual reality: dimensions determining telepresence. J Commun 42(4):73-93

Tang DN, Liao WH (2016) Impact of presence on cross-channel free-riding intention in online shopping. China Bus Mark 30(10):82-88. (in Chinese)

Thomas MJ, Wirtz BW, Weyerer JC (2019) Influencing factors of online reviews: an empirical analysis of determinants of purchase intention. Int J Electron Bus 15(1):43-71

Vana P, Lambrecht A (2018) Online reviews: star ratings, position effects and purchase likelihood (May 8, 2018). Tuck School of Business Working Paper No. 3108086. Available at SSRN: https://ssrn.com/abstract $=3108086$ or https://doi.org/10.2139/ssrn.3108086

Vries PD (2006) Social presence as a conduit to the social dimensions of online trust. persuasive technology. Springer, Berlin Heidelberg

Wang T, Wang K, Chen H (2015) The impact of temporal distance on the increase of the perceived usefulness of online reviews: from the perspective of the attribution theory. J Bus Econ 35(2):46-56

Wang W, Chen W, Kevin Z, Wang HW (2016) The success rate of crowdfunding and the persuasion of language style: an empirical study based on kickstarter. Manag World 32(5):81-98

Wang YD, Emurian HH (2005) An overview of online trust: concepts, elements, and implications. Computers Hum Behav 21(1):105-125

Willemsen LM, Neijens PC, Bronner F, De Ridder JA (2011) "Highly recommended!" The content characteristics and perceived usefulness of online consumer reviews. J Computer-Mediated Commun 17(1):19-38

Wu L, Shen H, Fan A, Mattila AS (2017) The impact of language style on consumers' reactions to online reviews. Tour Manag 59:590-596

Yu X, Xu ZL, Guo WJ (2017) Research on the influence of online product information presentation on customers' behavior intention. Inf Stud: Theory Application 40(10):80-84. (in Chinese)
Zhao HX, Wang XH, Zhou BG et al. (2015a) Relationship among interaction, presence and consumer trust in $\mathrm{B} 2 \mathrm{C}$ online shopping. Manag Rev 27 (2):43-54. (in Chinese)

Zhou MH, Li PM, Mou YP (2015b) Effects of online reviews on purchase intention of consumers: the mediation of psychological distance. Soft Sci 29 (1):101-104. (in Chinese)

\section{Acknowledgements}

This work was supported by Department of social sciences, ministry of education of China (No. 17YJA630076).

\section{Competing interests}

The authors declare no competing interests.

\section{Additional information}

Supplementary information is available for this paper at https://doi.org/10.1057/s41599 020-0387-6.

Correspondence and requests for materials should be addressed to S.-h.L.

Reprints and permission information is available at http://www.nature.com/reprints

Publisher's note Springer Nature remains neutral with regard to jurisdictional claims in published maps and institutional affiliations.

\begin{abstract}
Open Access This article is licensed under a Creative Commons Attribution 4.0 International License, which permits use, sharing, adaptation, distribution and reproduction in any medium or format, as long as you give appropriate credit to the original author(s) and the source, provide a link to the Creative Commons license, and indicate if changes were made. The images or other third party material in this article are included in the article's Creative Commons license, unless indicated otherwise in a credit line to the material. If material is not included in the article's Creative Commons license and your intended use is not permitted by statutory regulation or exceeds the permitted use, you will need to obtain permission directly from the copyright holder. To view a copy of this license, visit http://creativecommons.org/ licenses/by/4.0/.
\end{abstract}

(C) The Author(s) 2020 